\title{
A matter of transient anonymity: Discrimination by gender and foreignness in online auctions ${ }^{1}$
}

\author{
Emma von Essen $^{2}$ and Jonas Karlsson ${ }^{3}$
}

February 22, 2013

\begin{abstract}
:
This study shows that transient anonymity affects buyer discrimination based on seller's gender and foreignness in online auctions. Sellers' names are categorized by gender and foreignness. Half of the sellers' disclose their names in the usernames and the other half employ anonymous usernames, concealing gender and foreignness. After the price is set and the auction ends, the seller's name is always disclosed to the buyer by eBay. We explore buyers' discrimination in willingness to pay, measured as price. Furthermore, we study how buyers' discrimination in providing feedback is affected by sellers having an anonymous username or not (measured after seller name is known to the buyer). Our results indicate only some evidence of buyer discrimination in willingness to pay. However, interestingly we find that anonymity matters for discrimination; among sellers employing anonymous usernames male sellers with foreignsounding names receive fewer pieces of feedback than non-foreign female sellers. This is not found among groups of sellers whose names were revealed in the usernames. This discrimination is only present among female and not among male buyers.
\end{abstract}

Keywords: transient anonymity, discrimination, gender, foreignness, online auctions

JEL Classifications: C93, J15, J16, D12

\footnotetext{
${ }^{1}$ We are indebted to the individuals who collaborated with us as sellers. We are grateful to Kenneth Ritzén and comments from participants at Kista Folk High School. We would also like to thank Magnus Johannesson, Astri Muren, Anna Dreber, Ryszard Szulkin, Eskil Wadensjö and seminar participants at the $7^{\text {th }}$ Nordic Conference on Behavioral and Experimental Economics, Bergen, the Department of Economics at Stockholm University, and the Swedish Institute for Social Research at Stockholm University for providing fruitful comments. Financial support from Stockholm University's Linnaeus Center for Integration Studies (SULCIS) and the Jan Wallander and Tom Hedelius Foundation (e.vonessen) is gratefully acknowledged.

${ }^{2}$ Department of Economics, Stockholm University. Email: emma.vonessen@ne.su.se

${ }^{3}$ Swedish Institute for Social Research, Stockholm University. Email: jonas.karlsson@sofi.su.se
} 


\section{Introduction}

Unequal treatment is found in most societies with minority groups and women often faring the worst (for reviews see Anderson, Fryer and Holt, 2006; Riach and Rich 2002; Pager and Shepherd, 2008). ${ }^{4}$ Examples of discrimination range from the labor market (e.g. Bertrand and Mullainathan 2004), and housing market (e.g. Ahmed and Hammarstedt 2008); to the consumer market (e.g. Yinger 1998). A large number of these studies indicate that individuals are discriminated based on their names as signals of gender or foreignness. ${ }^{5}$ Throughout history anonymity of names or pseudonyms have been used to protect privacy and avoid unfair treatment; such as protection for whistleblowers or tip-offs to newspapers. Another example is the recent private as well as public calls to combat discrimination in the labor market by anonymous application procedures where minority groups and women receive an unbiased evaluation and thereof a fair chance of being invited to an interview. ${ }^{6}$

To our knowledge only a handful of studies in economics address anonymity in relation to situations of discrimination. Goldin and Rouse (2000) show that female musicians receive a higher probability of getting hired if auditions are anonymous, with no names disclosed and applicants perform behind a curtain. Edin and Lagerström (2006) study a situation where Swedish online job applicants can choose whether to reveal names (as well as other personal

\footnotetext{
${ }^{4}$ Heckman (1998) highlighted two main areas of caution when detecting discrimination; unobservable characteristics can differ between groups, and in a hiring situation the cut off value may for example differ between the groups.

${ }^{5}$ Arai and Thoursie (2009) show that there are also clear benefits in earnings for immigrants who changes their names in order to sound less foreign (from a Swedish perspective). On the other hand Fryer and Levitt (2004) find that name has no impact on a set of life outcomes in the U.S., controlling for circumstances around the time of birth. Arai et al (2011) do not find discrimination to be accumulative; it is male rather than female individuals in a minority group who experience the most discrimination.

${ }^{6}$ See for example the discussion in the press about the British government's call for anonymous application procedures: http://www.telegraph.co.uk/finance/jobs/hr-news/9009722/Government-proposes-anonymous-CVsto-end-discrimination.html, Access 2013-01-31.
} 
characteristics) or keep them anonymous. They find that women increase their probability of getting contacted by an employer with 15 percent, when gender is anonymous. Åslund and Nordström-Skans (2008) corroborates this result by finding that women and individuals with foreign names increase the probability of getting an interview when using anonymous application procedures. They show that anonymous applications also increase women's chance of receiving a job offer, i.e. after the interview stage when names and characteristics have been revealed. However, for individual with foreign (non Western) names the positive effect in interviews from of anonymous applications do not transfer into job offers. Bog and Kranandonk (2011) confirm these findings using data from Holland. These studies are the only two we are aware of that also go beyond the point of the assignment of interviews.

The internet communities provide increased possibility of being anonymous in a variety of social and economic interactions, private as well as in business. One simple way is to use an e-mail address or a username containing no information of the characteristics of the true user. For example at "customer to customer" sites, such as eBay approximately half of all usernames do not contain any information such as a signal (either of gender or foreignness). ${ }^{7}$ E-commerce is growing in both popularity and economic importance. eBay is the world's largest online marketplaces with more than 100 million active users globally, about 2 million in Sweden alone, and in 2011 the total value of goods sold was $\$ 68.6$ billion (as of the fourth quarter, 2011).

\footnotetext{
${ }^{7}$ Usernames without and with disclosing names are both common. A data set collected from the same market a year before the experiment shows that $50 \%$ of the accounts conceal their real name in the username (see table A1 in appendix).
} 
This study therefore investigate the causal effect of anonymity on buyer discrimination of the seller's gender and foreignness ${ }^{8}$ in an online market auction, by means of a lab-experiment in the online field. We let sellers with names with varying gender and foreignness sell a homogenous good on eBay, further we allow half of the sellers' to disclose the names in the usernames and the other half to use anonymous usernames. Once the auction is closed the anonymity is revealed by eBay sending an email including the seller's name to the winning bidder (i.e. the buyer). By design, in half of the observations buyers can self-select into an auction (or refrain from bidding), based on the name in the username.

First we investigate discrimination in willingness to pay, measured as the price the buyer pays. Further and most important we study the effect of anonymous usernames on discrimination after the auction is completed and names are common knowledge, by measuring the variation in provision of buyer feedback. In addition we measure how buyers pay and provide feedback by calculating how much time passes between the end of the auction and the respective actions. We also collect buyer characteristics.

To our knowledge this is the first study to investigate discrimination in feedback as well as the effect of transient anonymity on discrimination in online market auctions. Interestingly our results indicate that an anonymous username can inflict buyer discrimination post-auction, in the provision of feedback. Among sellers with anonymous usernames we find evidence of buyer discrimination; foreign male sellers receive a smaller amount of feedback than non-foreign female sellers. This effect is not present among groups of seller with non-anonymous usernames.

\footnotetext{
${ }^{8}$ Statistics Sweden and other Swedish authorities do not use the concepts of race or ethnicity. Data is collected by country of birth and citizenship. We therefore employ the concept of foreignness. In this study, foreignness relates to whether or not the name sounds foreign, from a Swedish perspective (see section 3, Design of the study).
} 
Interestingly, women, both foreign and non-foreign, seem to drive this discrimination. Unlike most previous studies we find no or little evidence of customer discrimination in willingness to pay, independent of whether the username is anonymous or not.

In contrast to offline commerce, the foundations of online commerce such as auctions can be characterized as anonymity, with little or no intrinsic motivation to trust or behave reciprocally. An online auction such as eBay can be described as a trust game. The seller posts an offer, including a description of the item and its condition, along with a starting bid. A potential buyer places a bid, indicating hers/his trust as willingness to pay for the item. Upon receipt of the money the seller is supposed to send the item to the buyer, of sound quality and with no delay. The buyer has to trust the seller to send the item (Bolton et al 2004). Further, all interactions on the world's largest online marketplace eBay $89 \%$ are one-shot. Thus, these transactions typically rely less on long term economic relationships than offline transactions (e.g. Resnick and Zeckhauser, 2002). Online trading also lacks the usual means of building trust; a buyer cannot inspect the product before bidding, or shake hands with the seller. As a substitute, internet marketplaces have implemented publically displayed reputational systems, i.e. feedback system (e.g. Bolton et al 2004; Bolton et al, 2008). These systems provide the interacting parties with a mean of building up reputation, by proving feedback ratings on each other's performance. Since providing feedback is voluntary, it can therefore be seen as an act of reciprocity (e.g. Dellarochas et al 2003).

Feedback systems seem to increases trust (e.g. Bolton et al 2012). Furthermore, sellers with good reputations are more likely to trade their goods and receive a price premium (e.g. Lucking-Reiley et al. 1999; Resnick and et al 2006). Feedback is of economic importance to the seller; more 
feedback implies an increased chance of selling and a greater willingness to pay among buyers (e.g. Jian et al 2010). In this environment, devoid of personal information, small social cues, such as names indicating group belonging; can affect behavior, such as an entry or a bidding decision online. With a feedback system this may be even more pronounced when the seller is new.

The online marketplace is an ideal area for studying discrimination, since it can be controlled more precisely than offline economic interactions, regarding for example structure and anonymity between trading partners. In the examples mentioned in the beginning discrimination came from employers, landlords, or salespersons. However, in this study we investigate discriminatory behavior arising from the customers (i.e. from the buyers). Customer discrimination has been investigated offline as well as online. There is evidence of customer price discrimination based on group belonging of the seller, in several markets; when selling baseball cards (e.g. Andersen and LaCroix, 1991; List, 2004) ${ }^{9}$, in tipping taxicab drivers (e.g. Ayres et al, 2011), and in restaurant tipping (e.g. Lynn et al, 2008). Customer discrimination also prevail online; Ayres et al (2011). find clear price discrimination for dark skinned sellers, studying the market for baseball cards on eBay. This finding is corroborated in non-auction online markets in the United States, in a study by Doleac and Stein (2010) on the sale of iPods. However, this result is only present in less competitive markets. Przepiorka (2012) conduct a study on eBay using Turkish and German male usernames to explore discrimination in willingness to pay. Turkish seller names receive lower pay in comparison with German seller names when selling DVDs and USB sticks. Also in this study discrimination is found only when competitive pressure is low. ${ }^{10}$

\footnotetext{
${ }^{9}$ Livingstone and List (2010) also conduct a similar study of the baseball card market online. They focus on seller discrimination, but find evidence also for buyer discrimination.

${ }^{10}$ Shohat and Much (2003) do not find price discrimination between German and Turkish sellers. The study by Przepiorka, (2012) includes a replication of this study, and does find price discrimination. Nunely et al, (2011) is
} 
Behavioral economics and psychology investigate differential treatments in situations resembling the online auction situation, using a trust game in lab or field experiments (see the review by Ostrom and Walker (eds), 2005). Some studies find evidence of discrimination in trust and reciprocity as a result of belonging to a minority (e.g. Fershtman and Gneezy, 2001; Buchan et al, 2002; Johansson-Stenman et al, 2008). Other studies do not find this (e.g. Bouckaert and Dhaene, 2004; Glaeser et al 2000) ${ }^{11}$. Fershtman and Gneezy, (2001) investigate both dimensions and find that discrimination in trust is only dependent on ethnicity among males. However, they find no ethnic discrimination in reciprocity. Moreover, in a literature review by Croson and Gneezy (2009) most studies find either no gender differences or they conclude that men are more trusting and women more reciprocal. However, there is evidence of the opposite direction (e.g Bellemar and Kröger, 2007).

In sum, the empirical literature on customer discrimination and discrimination in trust seems to point towards buyers either having a (dis)like for a particular group, i.e. taste-based discrimination (Becker, 1957), or a general social custom sustaining discrimination (Akerlof, 1980). However, it is often hard to rule out statistical discrimination (Arrow, 1973; Phelps, 1972). In our study there are sufficient amount of buyers and sellers in our market, buyers with a dislike of a particular group can therefore choose not to bid on a sellers based on the seller's username, among the non-anonymous seller groups. This is not possible among the seller groups with

another study using names as signal. They find that discrimination by race of the seller in willingness to pay decreases with increased market competition. They apply a "racial categorization" to the products sold, relating to the authors prior beliefs concerning the expected relative rates of bidding activity by race, to investigate the source of the discrimination. This is a method we believe involves problematic assumptions.

${ }^{11}$ Johansson-Stenman et al (2008) find that there is no discrimination in trust based on religion when using a trust game, but that differences are present when asking questions regarding trust in a survey. 
anonymous usernames. ${ }^{12}$ After the money and item has been sent the buyers provide feedback to the sellers. All sellers act the exact same way. This only leaves room for taste based discrimination, whereas discrimination in terms of willingness to pay can also include statistical discrimination.

The following section describes the features of eBay and the third section outlines our experimental design. Section 4 presents our hypotheses, section 5 reveals the data set we collected and section 6 presents our results and further analysis. The last section, 7, discusses the results.

\section{Buying and selling on eBay}

The vast majority of interactions between buyers and sellers are unique and anonymous. Swedish eBay is mainly a consumer to consumer business and is not dominated by small businesses, eBay account holders are usually both sellers and buyers. Buying and selling on eBay involves a sealed-bid-second price auction, where the winner pays the second highest bid (plus a minimum bidding increment). ${ }^{13}$ Firstly, when the auction is closed eBay sends an email, disclosing the names of the seller and buyer to each other and their respective emails so they can establish contact. Secondly, the buyer transfers the money for the item and the pre-specified delivery costs. Thirdly, when the seller receives the money s/he ships the good to the buyer. Finally, both buyers and sellers can: 1) rate the experience as positive or negative, or else not provide a rating, 2) write

\footnotetext{
${ }^{12}$ Slonim and Guillen (2010) conduct a trust game with and without the possibility of selecting partner by gender. Subjects that are able to select are found to trust the opposite gender more.

${ }^{13}$ The bidder states a reservation price and this maximum price eBay will use to bid for her/him by proxy. As more buyers submit their reservation prices the bid rises by the minimum increment until the second highest reservation price is surpassed. This structure has sometimes been shown to impose last-minute bids (Roth and Ockenfels 2002). eBay instructs bides not to place last-minute bids.
} 
a short comment, 3) rate the experience on a scale from 1 to $5 .{ }^{14}$ The buyer and seller have 60 days after an auction has ended to use the feedback system. All ratings are immediately displayed publically on the seller and buyers eBay-web page. Before the seller or buyer receives ten unique ratings the account will be publically displayed as "new" to the market. After ten ratings, eBay displays an average total grade, and the account holder is no longer described as new. However, previous literature has found five ratings to be enough to learn the eBay auction and feedback system, and being treated accordingly by others in the market (see for example Jian et al 2010).

\section{Design of the study}

Swedish eBay requires each account to be connected to a Swedish social security number, i.e. all buyers and sellers are registered by the Swedish tax authorities as living in Sweden. We therefore collaborated with a group of sixteen individuals that were asked to create new eBay seller accounts in their names, for us to manage. ${ }^{15}$ In addition to this we also created hotmail accounts using their names in order to provide payment information to buyers. The names of the sellers we collaborate with are categorized by gender and whether or not the name sounds foreign. Firstly, our non-foreign sellers all have patronyms as surnames (ending with -son) and common Swedish first names. Patronyms are the most common Swedish surnames. ${ }^{16}$ Secondly, as sellers with foreign names we asked a sample of twenty students at Stockholm University to match full names (first names and surnames) of potential sellers to a gender and a region (coded into six regions according to Statistics Sweden; Latin- and South America, Middle East and North Africa, EU15+,

\footnotetext{
${ }^{14}$ The buyer is asked to rate the seller in four different categories; item as described, communication, shipping time, and shipping and handling charges. The seller only rates the buyer in one category: time until payment. eBay allows an average total across these categories to be publically available. Average grades on eBay are generally high with very little variation, rarely below an average of 4.5 .

15 The experiment was approved by a committee vetting the ethics of research involving humans (EPN Stockholm, $19^{\text {th }}$ October 2011).

${ }^{16}$ Statistics of all first and surnames of Swedish citizens are available at Statistics Sweden.
} 
the rest of Europe, the rest of Asia, the rest of Africa). We only collaborate with sellers whose names all students could match correctly with gender and the region of Middle East and North Africa. This is a similar categorization of names as used in Arai et al (2011). In another paper Arai and Thoursie (2009) found a high positive correlation between a judgment-based regionalcoding of names and the actual regions of birth. This indicates that identifying the region of birth by observing an individual's name is relatively straightforward.

We asked half of our seller's to create a usernames comprising of their real first names (nonanonymous usernames). The other half are asked to create usernames consisting of their initials (anonymous usernames). The usernames comprise only the first name and not the surname, since this is a common feature of usernames (see for example Przepiorka, 2012). With the treatment dimensions of anonymity of username, gender and foreignness the study consists of eight groups in total, with two seller names in each category. Table 1 displays the entire list of seller categories.

Table 1. The Eight Seller name categories*

\begin{tabular}{ll}
\hline Non-anonymous seller names & Anonymous seller names \\
\hline & \\
Male foreign names & Male foreign names \\
Male non-foreign names & Male non-foreign names \\
Female foreign names & Female foreign names \\
Female non-foreign names & Female non-foreign names \\
\hline
\end{tabular}

*The list of seller names used in the study can be found in appendix Table A2. There are 2 names in each category.

The sellers sell cinema vouchers. A cinema voucher is a homogeneous good where the price and quality is common knowledge, implying a good internal validity. These vouchers are commonly given as presents between individuals and from employers to employees; they are bought and sold offline as well as online. All buyers face the risk of fraud, such as the voucher having already been used, or from bad seller conduct, such as the seller providing the good late. In this 
study, however, there is little risk of receiving the good in a poor quality. Trust in this experiment therefore relates more to risk of fraud and seller misconduct than receiving a good of lower than expected quality. Compared to the online baseball card market used in Livingstone and List (2010), for example, with hundreds of thousands of ongoing auctions, the market for cinema vouchers on Swedish eBay seems to be rather small. In August a year before the experiment there was on average 70 ongoing auctions each day; the same number of ongoing auctions as during our experiment.

\subsection{The experimental procedure}

Four sellers, two from the anonymous seller group and two from the non-anonymous group, place vouchers sequentially on the market every day. Two auctions start before lunch and two in the afternoon. ${ }^{17}$ Each auction places two vouchers on sale each time, since two is the most common number of vouchers auctioned in this market. We also use a standard presentation of the vouchers, and randomly employ one out of three commonly used pictures of cinema vouchers as well as one of three standard voucher descriptions. The lowest bid is set to $1 \mathrm{SEK}$. When the bidding starts the only information available to potential bidders is the seller's username and previous feedback. All of our sellers start as new with no previous feedback ratings. ${ }^{18}$ When the auction closes, the real names of the buyers and sellers are revealed in an e-mail sent by eBay, but only to each other. ${ }^{19}$ We then send an e-mail to the winning buyer with payment instructions, using a standardized text. No email correspondence is initiated before an auction is closed. As with most transaction on Swedish eBay, we use bank-to-bank transfers as the method of

\footnotetext{
${ }^{17}$ The starting times, before and after lunch, are also randomly chosen (before lunch between 07:00-12:00 and after lunch 13:00-20:00). The average length of an auction in this market is five days; we apply the same length.

${ }^{18}$ The number of feedback ratings became endogenous during the experiment. In the analysis we control for whether the seller is new or experienced before the auction ended.

${ }^{19}$ In addition to real names addresses are also disclosed when the auction ends. We exogenously imposed addresses from the same local area to keep everything constant across name groups apart from the names themselves.
} 
payment. ${ }^{20}$ The same day as the payment is registered we send the vouchers to the buyer through the regular post.

After an auction has closed the buyer and seller can rate each other's behavior. According to Jian et al (2010) the buyers are first to provide feedback $85 \%$ of the time, and the majority of buyer feedback is provided rather quickly or not at all. We therefore rate the buyer as soon as the buyer has rated us as a seller. In order to capture buyers who only provide feedback after the seller does so, we give feedback to the buyers after ten days, provided payment has proceeded. ${ }^{21} \mathrm{~A}$ recent paper confirms that, on average, a well-behaving seller receives feedback after ten days (Cabral and $\mathrm{Li}, 2012$ ). When our sellers rate the buyers we provide a common feedback; a positive rate, a grade point of 5 and a brief standardized positive comment. Hence, auctions are carried out using the same seller conduct across categories, all acting as perfect sellers. Buyers are not aware of being part in an experiment. Figure 1 in the appendix displays a screen dump from one of our seller's publically available accounts, taken from approximately the middle of the experiment.

We measure discrimination in willingness to pay, and in provision of feedback. ${ }^{22}$ To explore the possible effect of anonymity or information availability when entering an auction, we analyze discrimination in the provision of feedback for non-anonymous and anonymous seller groups separately. In addition, we assess how the buyers pay and provide feedback by measuring the number of days to the respective actions once the auction has ended. We also explore the source of the potential discrimination by looking at buyers' characteristics, namely gender and the

\footnotetext{
${ }^{20}$ We created different account numbers, in case a buyer bought from more than one of our sellers.

${ }^{21}$ On 10 occasions the buyer provided payment after ten days. These buyers receive first feedback after they have paid. Our results do not differ qualitatively if we exclude or include them in the analysis.

${ }^{22}$ Negative ratings are very rare in general and in the experiment we acted as perfect sellers.
} 
foreignness of the buyer's name. We categorize buyers' names by employing a similar procedure as that used for the sellers' names. We asked four of our sellers; a man and a woman with foreignsounding name and their counterparts with non-foreign-sounding names match the list of buyer names to gender and region. We also asked whether they perceived the name as sounding foreign or not. In the main analysis we categorize according to the question of whether the name sounds foreign or not. ${ }^{23}$

\section{Hypotheses and summary of results}

When gender and foreignness interacts Arai et al (2011) find that foreign men in Sweden are the group which fares the worst. Moreover, Fershtman and Gneezy (2001) find ethnic discrimination in trust to be present only among men. We therefore use male sellers with foreign sounding names as the reference category in the regressions. The interaction of gender with foreignness is analyzed by comparing the outcome between each name category. Discrimination is also analyzed separately for anonymous and non-anonymous usernames. Table 2 provides a summary of our hypotheses and results.

\subsection{Anonymity and discrimination}

This study investigates a particular good with common value and quality, thus reducing the risk of bad quality. The requirement for a social security number also reduces the risk of fraud. Previous studies with similar products find price discrimination (e.g. Ayres et al, 2011; Nunely et al, 2011; Doelac and Stein, forthcoming; List and Livingstone, 2010; Przepiorka, 2010). We

\footnotetext{
${ }^{23}$ To investigate whether buyer discrimination is an in-group behavior based on the perception of the name being connected with the region of the Middle East and North Africa, we categorized buyers' names as being foreign to those that are matched with this region. All our results stay qualitatively the same when employing this categorization of buyer names.
} 
expect discrimination in willingness to pay, with foreign male sellers receiving the lowest pay (in the non-anonymous group). We do not expect to find discrimination among the anonymous group.

Fershtman and Gneezy (2001) find no ethnic discrimination in reciprocity and Buchan et al (2002) find that individuals are no more trustworthy towards either gender. If the buyer has information about the seller when entering an auction, the buyer can choose to base his/her entry and payment decisions on this. This possibility of self-selection can make the buyers less inclined to employ differential treatment in the provision of feedback when the auction has ended compared to when there is no room for self-selection (when the buyer has no information on the name about the seller). For the seller categories with non-anonymous usernames we expect little or no differential treatment in the provision of feedback. If buyers (dis)like or have a prejudice against a specific group, and are only exposed to information after having interacted with a seller from this specific group, it may trigger differential treatment in the provision of feedback. In Areys et al (2011) customers cannot chose the taxicab driver and there is evidence of discrimination against Afro-American taxicab drivers in terms of tipping. For the seller categories with anonymous usernames we expect differential treatment in the provision of feedback, with male sellers with foreign sounding names receiving the lowest share.

In addition we measure time which elapses between the end of the auction and payment/feedback conditional on having paid or having provided feedback (reciprocated). We have no expectation of the impact of anonymous names on discrimination in these two variables. 
Table. 2. Summary of hypotheses and results.

\begin{tabular}{|l|l|l|l|l|}
\hline Variable & Group studied & Hypothesis* & Results & $\begin{array}{l}\text { Hypothesis } \\
\text { supported? }\end{array}$ \\
\hline \hline Willingness to pay & Non-anonymous & $\begin{array}{l}\text { MFS }<\text { MNS } \\
\text { MFS }<\text { FNS } \\
\text { MFS }<\text { FFS }\end{array}$ & $\begin{array}{l}\text { MFS } \leq \text { MNS } \\
\text { MFS=FNS } \\
\text { MFS=FFS }\end{array}$ & $\begin{array}{l}\text { Yes } \\
\text { No } \\
\text { No }\end{array}$ \\
\hline Share of feedback & Non-anonymous & MFS $\leq$ MNS & MFS=MNS & Yes \\
& & MFS $\leq$ FNS & MFS=FNS & Yes \\
& & MFS $\leq$ FFS & MFS=FFS & Yes \\
\cline { 2 - 5 } & \multirow{2}{*}{ Anonymous } & MFS $<$ MNS & MFS $\leq$ MNS & Yes \\
& & MFS $<$ FNS & MFS $<$ FNS & Yes \\
& & MFS $<$ FFS & MFS=FFS
\end{tabular}

MFS= Male foreign sounding name MNS=Male non-foreign sounding name FFS=Female foreign sounding name FNS=Female non-foreign sounding name. In the results column, = indicates that the hypothesis of a difference could not be rejected in a regression without and with additional control variables. $\leq$ in the result column indicates that the hypothesis was rejected with borderline significance in a regression without additional control variables.

*Regarding the comparisons between the other name categories we have no prior. Results are provided in appendix.

\section{Data}

The study was carried out between $30^{\text {th }}$ of April and $30^{\text {th }}$ of August 2012 in the market for cinema vouchers on Swedish eBay. We conducted a total of 461 auctions. Interacting more than once may influence trust and induce dependence between observations, so we therefore exclude all but the first interaction between each buyer and seller. ${ }^{24}$ Furthermore, 15 observations involved communication problems with the buyer and they are therefore excluded from the analysis. In total our data set comprises 426 observations. We are interested in investigating whether the anonymity of the username affects discriminatory treatment between seller categories before and after the real names are revealed. We therefore separate the analysis for these two main groups; sellers with anonymous usernames and sellers with non-anonymous usernames.

\footnotetext{
${ }^{24}$ This occurred only 20 times. Hence, more than $95 \%$ of our interactions were therefore one-shot. This is in line with previous literature (Resnick and Zeckhauser, 2002).
} 
Table 3 shows a summary of our four main variables together with buyers' characteristics. The average price of two vouchers is 140 SEK, or approximately $70 \%$ of the original price. $70 \%$ of our paid auctions received feedback, and all feedback received was positive. The buyers in our data set are heterogeneous with respect to gender and foreign sounding names, residential area, and previous feedback.

Table 3. Summary statistics.

\begin{tabular}{llll}
\hline Variables & Mean & Sd & N \\
\hline Price & 140.18 & 10.70 & 426 \\
\# Feedback* & 0.70 & 0.46 & 405 \\
Days to payment & 2.31 & 2.59 & 405 \\
Days to feedback & 8.52 & 10.06 & 287 \\
Female buyer & 0.49 & 0.50 & 426 \\
Foreign name buyer & 0.35 & 0.48 & 426 \\
Big city buyer & 0.49 & 0.50 & 426 \\
New buyer** & 0.20 & 0.40 & 426 \\
Buyer has negative*** & 0.32 & 0.47 & 426 \\
\hline \hline
\end{tabular}

* Feedbacks is only counted if auction rendered a payment.

** 1 if buyer has 5 or less pieces of feedback at end of auction, 0 otherwise.

*** 1 if buyer has at least 1 pieces of negative feedback at end of auction, 0 otherwise.

\section{Results}

Throughout the analysis we use Ordinary Least Square regressions. ${ }^{25}$ All regressions are presented using dummies for each seller group, with and without additional control variables. As additional control variables we use whether or not the buyer is female and whether or not they have a non-foreign sounding name, as well as a set of variables previously shown to be important in the outcomes of auctions on eBay. These variables include; whether the buyer and seller are

\footnotetext{
${ }^{25}$ We also altered the specifications of the regressions; for willingness to pay and time to feedback we also ran Tobit regressions (lower limit set to 115 and upper limit set to 175; and lower limit set to 0 and upper limit set to 60 respectively), and for share of feedback we also ran a logit regression. This does not qualitatively change our results.
} 
new to eBay, the buyer's previous amount of feedback, whether the buyer has had at least one piece of negative feedback, whether the buyer lives in a big city or not, and day fixed effects.

\subsection{Discrimination in willingness to pay}

The regressions displayed in Table 4 are carried out on the sellers with non-anonymous usernames. In contrast to many other studies of discrimination, offline as well as online, we find little or no evidence of discrimination in willingness to pay, measured by the price the buyer pays, by name category among the non-anonymous seller groups. On averages all groups seem to receive 140 SEK for two vouchers. Point estimates indicate less favorable pay for male sellers with foreign-sounding names compared to all other groups, but this is not significant. When including additional controls a borderline effect occurs. Male sellers with foreign-sounding names seem to receive 3.3 SEK less for the same product compared to male sellers with nonforeign sounding names $(\mathrm{p}=0.08)$. If we investigate this further and compare the group of male foreign sellers with all other seller categories this discrimination disappears $(p=0.21) .^{26}$

Table 4. Willingness to pay.*

\begin{tabular}{lll}
\hline VARIABLES & Non-anonymous & Non-anonymous \\
2 & 1 & $3.334^{*}$ \\
Male non-foreign seller name & 2.009 & $(1.820)$ \\
& $(2.022)$ & 1.463 \\
Female non-foreign seller name & 1.180 & $(1.773)$ \\
Female foreign seller name & $(1.977)$ & 2.364 \\
& 2.169 & $(1.707)$ \\
Additional controls & $(1.897)$ & Yes \\
Observations & No & 217 \\
R-squared & & 0.255 \\
\hline
\end{tabular}

${ }^{26}$ In addition we conducted a sample size analysis comparing willingness to pay between male sellers with foreignsounding names. We would need 979 additional auctions to reach a significant difference, assuming $80 \%$ power. Calculating the effect size for this borderline discrimination; the proportion of the variance attributed to this effect taking the error size into account is 0.018 . 
Robust t-statistics in parentheses. $* * * \mathrm{p}<0.01, * * \mathrm{p}<0.05, * \mathrm{p}<0.1$. Standard errors are clustered on buyer username *The regression is performed on sellers with anonymous usernames, when selection into auction by name is possible.

There is no discrimination among the anonymous sellers groups. To compare whether there are general differences between having an anonymous or non-anonymous user name we test whether willingness to pay differs between the groups. We find no significant difference (See Table A3 in the appendix). ${ }^{27}$ Additionally, the share of buyer characteristics is similar between the anonymous and non-anonymous groups. See Table A4 in the appendix.

Being a new seller (having less than 5 pieces of feedback) has a clear negative effect on willingness to pay. This corroborates previous literature, and indicates that receiving feedback has a clear economic impact for the seller on eBay. A new seller receives on average 11 SEK less compared to an experienced seller $(\mathrm{p}<0.01)$. Results for additional variables and comparisons between other seller categories are found in the appendix, Table A6.

Differences in the seller's level of experience can be important in terms of discrimination. There is, however, no reason to believe that experience has different implications for sellers with anonymous and non-anonymous usernames. During the experiment the feedback the sellers received from the buyers became endogenous. We have too few observations to compare willingness to pay between all seller categories at each feedback level. In the regressions we control for being an experienced seller or not: 1 if the seller has at most 5 pieces of feedback, 0 otherwise. Increasing the number of pieces of feedback from 5 to 10 strengthens the discrimination of male foreign sellers in regression 2. Discrimination in willingness to pay seems

\footnotetext{
${ }^{27}$ To make sure that willingness to pay does not change for a particular name category we also compared each seller category which revealed their name with a baseline constructed from the average willingness to pay from all groups which conceal their names. We do not find any significant differences (see appendix Table A5).
} 
to be dependent on the number of pieces of feedback the seller has, but this relationship do not appear to be linear.

\subsection{Discrimination in share of feedback}

Regressions 1 and 2 in Table 5 show that the share of feedback is constant across seller name categories when the names are present in the usernames (non-anonymous). Feedback is measured as 1 if the buyer provided feedback, 0 otherwise. Regressions 3 and 4, on the other hand, indicate differential treatment by seller categories. In terms of average differences there is borderline significance between male sellers with foreign-sounding and female sellers with non-foreign sounding names (regression 3: $\mathrm{p}=0.07$ ). When including control variables, male sellers with foreign-sounding names receive less feedback compared to both males and female sellers with non-foreign-sounding names (regression 4 males: $\mathrm{p}=0.04$; females: $\mathrm{p}=0.02$ ). ${ }^{28}$ See appendix Table A7a for results regarding controls such as buyer characteristics, and comparison between other seller categories.

Table 5. Share of feedback.

\begin{tabular}{|c|c|c|c|c|}
\hline VARIABLES & $\begin{array}{l}\text { Non- } \\
\text { anonymous } \\
1 \\
\end{array}$ & $\begin{array}{l}\text { Non-anonymous } \\
\mathbf{2} \\
\end{array}$ & $\begin{array}{l}\text { Anonymous } \\
\mathbf{3} \\
\end{array}$ & $\begin{array}{l}\text { Anonymous } \\
\mathbf{4} \\
\end{array}$ \\
\hline Male non-foreign seller name & $\begin{array}{l}-0.084 \\
(0.090)\end{array}$ & $\begin{array}{l}-0.061 \\
(0.049)\end{array}$ & $\begin{array}{l}0.109 \\
(0.091)\end{array}$ & $\begin{array}{l}0.126^{* *} \\
(0.062)\end{array}$ \\
\hline Female non-foreign seller name & $\begin{array}{l}-0.047 \\
(0.091)\end{array}$ & $\begin{array}{l}0.043 \\
(0.058)\end{array}$ & $\begin{array}{l}0.160 * \\
(0.088)\end{array}$ & $\begin{array}{l}0.133^{* *} \\
(0.059)\end{array}$ \\
\hline Female foreign seller name & $\begin{array}{l}-0.028 \\
(0.085)\end{array}$ & $\begin{array}{l}0.023 \\
(0.053)\end{array}$ & $\begin{array}{l}0.060 \\
(0.092)\end{array}$ & $\begin{array}{l}0.036 \\
(0.061)\end{array}$ \\
\hline Additional control variables & No & Yes & No & Yes \\
\hline $\begin{array}{l}\text { Observations } \\
\text { R-squared }\end{array}$ & $\begin{array}{l}206 \\
0.004\end{array}$ & $\begin{array}{l}206 \\
0.660\end{array}$ & $\begin{array}{l}198 \\
0.017\end{array}$ & $\begin{array}{l}198 \\
0.578\end{array}$ \\
\hline
\end{tabular}

Robust t-statistics in parentheses. ${ }^{* * *} \mathrm{p}<0.01, * * \mathrm{p}<0.05, * \mathrm{p}<0.1$. Standard errors are clustered on buyer username.

${ }^{28}$ Calculating the effect sizes; the proportion of the variance attributed to this effect taking the error size into account are 0.024 and 0.029 for male and female sellers with non-foreign names respectively. 
Buyers can provide feedback before or after the seller provides feedback (i.e. before and after ten days). In the first case buyers run the risk of receiving negative feedback from sellers and in the second buyers run no such risk. We ran the four regressions from Table 5 separately, for both buyers providing feedback before the sellers provide feedback and vise versa. The pattern is qualitatively the same for both types of buyers. The number of pieces of feedback the seller has does not seem to relate to the share of feedback given by buyers. Hence in our sample experience of a seller do not affect the share of feedback buyers provide $(\mathrm{p}=0.895)$. See appendix tables A7bc for figures.

Probing further into buyer characteristics; what type of buyer groups that may drive this discrimination we separated regression 3 and 4 based on buyer gender and whether the buyer has a foreign sounding name or not. In contrast to other studies we find that this discrimination is only present among women and not among men; women with both foreign and non foreign names. Se appendix table A7d.

\subsection{Days to payment and days to feedback}

We also measure whether the manner in which buyers show trust, measured as days to payment, differs between seller categories. Days to payment is measured from the day the auction ended. 21 buyers did not pay at all, and these are equally distributed across seller categories. We find no differences in time to payment by seller category among the buyers facing non-anonymous sellers. On average, all groups receive payment after little more than 2 days. Among the buyers who face the anonymous name categories the results differ; male sellers with foreign-sounding names receive payment approximately 1 day faster than female sellers with foreign-sounding 
names (regression3: $\mathrm{p}=0.02$, regression4: $\mathrm{p}=0.02$ in appendix table A8a). A quick response can be interpreted as being either negative or positive. Differentiating between categories through a shorter time to payment can, for example, imply that the buyer wants to end the interaction as quickly as possible. Therefore we additionally ran regressions separately for buyers who provided feedback and those who did not (among the anonymous seller group). The discriminatory behavior in Table 6 is only present among buyers who did not provide feedback, indicating buyers wish to leave the interaction as fast as possible. See appendix table A8b-c.

We also measure if buyers differ in terms of how they reciprocate, measured as days to feedback. To our knowledge time to feedback has not been explored in previous literature and this section is therefore more or less exploratory. Days until feedback is measured from the day the auction ends. ${ }^{29}$ We find that when sellers employ anonymous usernames discrimination between sellers categories occur. Males seem to receive feedback faster than female sellers with foreign-sounding names when including control variables $(\mathrm{p}=0.05)$. See appendix table A9a-b. Feedback which is provided late or at the last-minute could be because a buyer (or seller) wants to leave negative feedback and minimize the risk of retaliation. We only receive positive feedback. Even if this discrimination can be hard to interpret, the results show that using anonymous names spur differentiation in how buyers treat seller categories.

To summarize: In contrast to many previous studies we find only little evidence of customers' willingness to pay being dependent on gender and foreignness of seller username. However, we do find that anonymity of username affects the differential treatment by gender and foreignness in

\footnotetext{
${ }^{29}$ We also measured the number of days to feedback starting from the day of payment, and as hours to feedback. These measures provide qualitatively the same results.
} 
post-auction behavior. When employing anonymous usernames we find that male sellers with foreign-sounding names receive a smaller amount of feedback than non-foreign female sellers. This pattern is not present among groups of sellers with non-anonymous usernames. This is further found only among women buyers, not among men.

\subsection{Further analyses}

Discrimination in willingness to pay seems to be dependent on the number of pieces of feedback the seller has, and this relationship do not appear to be linear. To further investigate how experience and discrimination interrelate we ran all the regressions including interactions of being a new seller in all the respective seller categories. All seller categories receive better pay when they are experienced. The provision of feedback, on the other hand, does not seem to depend on experience, for any of the seller groups. Looking further into the variable new seller we notice that it takes approximately the same number of auctions for all seller categories to receive five pieces of feedback, both for anonymous and non-anonymous seller groups.

Several studies show that increased competition in online markets decrease price discrimination (e.g. Ayres et al, 2011; Nunely et al, 2011; Doelac and Stein, 2010; List and Livingstone, 2010; Przepiorka, 2010). Compared to the baseball card market in the U.S., for example, the market for cinema vouchers in Sweden is small. On the other hand there seem to be more buyers than sellers in this market, creating competition among buyers, which could potentially explain our findings of little discrimination in willingness to pay. ${ }^{30}$ A large market share could also potentially explain why we find no discrimination. We did not continuously estimate the size of the market share we had each day, but we did not seem to affect the market price. The average price level for selling

\footnotetext{
${ }^{30}$ The vast majority of our sellers were one-shot, and we had on average 27 bids per auction.
} 
two cinema vouchers was 151 SEK in August 2011 and the price our sellers received on average during August 2012 was 149 SEK. We also collected prices from auctions ending a month after the experiment closed. The average price for two vouchers in September 2012 was 149 SEK (see appendix Table A1).

We probe deeper into the feedback by creating a variable defined as 1 if the buyer included a positive text with the feedback and 0 otherwise. Approximately $70 \%$ of all buyers provide a text message. This does not differ by seller name category, irrespective of whether they have anonymous usernames or not. We also investigate discrimination in feedback further by constructing a variable that describe the number of buyers who send an email which clearly signals distrust. 15 of the buyers sent such an email. All of these emails are received equally across seller names.

A voucher is a homogeneous good where the price and quality is common knowledge, thus providing good internal validity. This potentially implies lower external validity for this study. The proportion of women buyers in our sample of buyers is the same as in the general population. On the other hand, we seem to have a large share of buyers with foreign-sounding names. We have no means of looking into the socio-demographics of our buyers. Customers buying cinema vouchers on eBay could potentially care more about small earnings and have more time compared to the general population. However, during April 2008 and March $200962 \%$ of the Swedish population aged 17-64 had bought goods online (see Statistics Sweden, 2010). Due to its potentially lower external validity we should be careful not to draw direct inferences from this study to other settings and groups. Nevertheless, this study provides an interesting and important 
example of how anonymity can affect customer discrimination and can be employed with ease in future online research.

\section{Discussion}

In this experiment we allow sellers with names varying by gender and foreignness to sell a homogenous good in an online auction, all acting identically and as perfect sellers. Despite this setting, which can be viewed as a lower bound, we find some indications of buyer discrimination of foreign male sellers in willingness to pay. However, in contrast to most other previous studies this is only a marginal effect. More interestingly, this study presents a novel analysis in two respects; firstly we investigate discrimination in the feedback system, secondly we investigate how transient anonymity, concealing gender and foreignness in the usernames, can affect buyer discrimination in feedback. This study finds evidence that employing anonymous usernames affects buyer discrimination in feedback, measured after the auctions has ended and names are revealed by eBay. Male sellers with a foreign-sounding name receive a lower share of feedback compared to sellers with non-foreign-sounding names. This discrimination only occurs if the sellers' usernames are anonymous, and no information regarding gender or foreignness was provided when the buyers entered the auctions. Interestingly, this discrimination seems to be driven by female buyers, both with foreign and non-foreign sounding names. In addition we find that employing anonymous usernames also affect discrimination in time to payment and time to feedback.

Finding only little evidence of discrimination in willingness to pay, may be an indication that our study takes place in a perfect market where feedback is the most important determinant of the price. Nevertheless, a thick market where there are a sufficient amount of buyers and sellers can 
allow for self-selection without affecting the price. This possible selection may explain why we find discrimination in feedback among the sellers with anonymous usernames. However, buyer characteristics that we are able to measure seem to be similar among seller categories in the anonymous and non-anonymous groups. Self-selection among buyers can be based on other characteristics than we measure, such as taste for interacting with women and individuals with foreign names. This could possibly explain differences in willingness to pay in less competitive markets, found by other studies using homogenous goods (e.g. Doleac and Stein, forthcoming; Prezipiorka 2012).

In most studies of online markets the reputational feedback system is assumed to have no bias. Our study indicates that the system may contain a bias when employing transient anonymity. The amount of feedback a seller has is of economic relevance since it increases both the sales and the profit of the seller. Thus, there may be price differences between sellers of different gender and foreignness among the group employing anonymous usernames. We are not able to explore this, due to data limitations. It is important for marketplaces like eBay to investigate this further.

Our results on price and feedback in online auctions are similar to the previous findings on interviews and job offers in hiring, using transient anonymity (see Åslund and Nordström-Skans 2008; Bog and Kranandonk, 2011). In contrast with these studies we find little discrimination in the first stage (in price), and discrimination emerges only in the case when buyers after the auctions ends are confronted with the names of the sellers (in feedback). Hence, in our study employing transient anonymity in online auctions seems to cause discrimination rather than avoiding it. 
Taking actions against discrimination is perhaps easier online than offline; for example, by changing institutional settings such as the feedback structure and the information that buyers and sellers have to reveal before an auction. Reputation online spreads rapidly, at a low cost, for example, via feedback systems. Besides bearing economic relevance within the market; feedback systems may have other important implications such as brand building, product development, and quality assurance (see Cook et al, 2009 for a review). It is therefore of considerable importance to further the understanding of the mechanisms behind discrimination of gender and foreignness in online markets; such as varying the degree of anonymity, or different possibilities of assessing the quality of the product. 


\section{References}

Andersen, T., and LaCroix, J. (1991). Customer Racial Discrimination in Major League Baseball, Economic Inquiry, 29:4, 665-667.

Anderson, L., Fryer, R., and Holt, C. (2006). Discrimination: Experimental evidence from psychology and economics, In Rogers, W. (Ed.), Handbook on the Economics of Discrimination, 97-115, Edward Elgar Publishing.

Ahmed, A., and Hammarstedt, M. (2008). Discrimination in the rental housing market: A field experiment on the internet. Journal of Urban Economics, 64:2, 362-372.

Akerlof, G. (1980). A Theory of Social Custom, of which Unemployment may be One Consequence, Quarterly Journal of Economics, 94:4, 749-775.

Arai, M. and Skogman T., P. (2009). Renouncing Personal Names: An Empirical Examination of Surname Change and Earnings, Journal of Labor Economics, 27.

Arai, M., Bursell, M., and Nekby, L. (2011). The Reverse Gender Gap in Ethnic Discrimination: Employer Priors against Men and Women with Arabic Names, DULBEA Working Papers 11-09.

Arrow, K. (1973). The theory of discrimination. In O. Ashenfelter \& A. Rees (Eds.), Discrimination in Labor Markets, 3-33, Princeton University Press.

Åslund, O., and Skans, O. (2007). Do anonymous job application procedures level the playing field?, IFAU - Institute for Labour Market Policy Evaluation. Working Paper Series.

Ayres, I. and Banaji, M., and Jolls, C. (2011). Race effects on ebay, Available at SSRN: http://ssrn.com/abstract $=1934432$

or http://dx.doi.org/10.2139/ssrn.1934432.

Becker, Gary S. 1957. The economics of discrimination. Chicago: University of Chicago Press.

Bellemare, C., and Kröger, S. (2007). “On Representative Social Capital.” European Economic Review, 51:1, 183-202.

Bertrand, M., and Mullainathan, S. (2004). Are Emily and Greg more employable than Lakisha and Jamal? A field experiment on labor market discrimination, American Economic Review, 94:4, 991-1013.

Bog, M. and Kranandonk, E. (2011). Blindfolded Recruiting.

Bolton, G. E., Greiner, B. and Ockenfels, A., (2012). Engineering Trust - Reciprocity in the Production of Reputation. Management Science, doi:10.1287/mnsc.1120.1609. 
Bolton, G., E., Loebbecke, C., and Ockenfels, A. (2008). How social reputation networks interact with competition in anonymous online trading: an experimental study. Journal of Management Information Systems. 25, 145-169.

Bolton, G., Katok, E., and Ockenfels, A. (2004). How Effective Are Electronic Reputation Mechanisms? An Experimental investigation, Management science. 50:11, 1587-1602.

Bouckaert, J., and Dhaene, G. (2004). Inter-ethnic trust and reciprocity: results of an experiment with small businessmen, European Journal of Political Economy, 20:4, 869-886.

Buchan, N. R., Croson , R., T., A., and Dawes, R., M. (2002). Swift Neighbors and Persistent Strangers: A Cross-Cultural Investigation of Trust and Reciprocity in Social Exchange, American Journal of Sociology, 108:1, 168-206.

Cabral, L., and Li, L., I. (2012). A Dollar for Your Thoughts: Feedback-Conditional rebates on eBay, NYU Working Paper No.

Cook, K., S., Snijders, C., Buskens, V., and Cheshire, C. (eds.) (2009). eTrust: Forming Relationships in the Online World. New York: Russell Sage Foundation Publications

Croson, R., Gneezy, U. (2009). Gender Differences in Preferences, Journal of Economic Literature, 47:2, 448-74

Dellarocas, C. (2003). The Digitization of Word of Mouth: Promise and Challenges of Online Feedback Mechanisms, Management Science, 49:10, 1407-1424.

Doleac, J., L., and Stein, L., C., D. (2010). The Visible Hand: Race and Online Market Outcomes. Forthcoming in Economic Journal.

Edin P-A \& J Lagerström (2006). Blind dates: quasi-experimental evidence on discrimination. IFAU working paper 2006:4.

Fershtman, C., and Gneezy, U. (2001). Discrimination in a segmented society: An experimental approach, Quarterly Journal of Economics, 116, 351-77.

Fryer, R., G., and Steven D., L. (2004). Causes and consequences of distinctively black names, Quarterly Journal of Economics, 119:3, 767-805.

Glaeser, E., L., Laibson, D., I., Scheinkman, J., A., Soutter, C. L. (2000). Measuring Trust, The Quarterly Journal of Economics, 115, 811-846.

Goldin, C., and C. Rouse (2000). Orchestrating Impartiality: The Impact of "Blind" Auditions on Female Musicians," American Economic Review, 90:4, 715-41.

Heckman, J. (1998). Detecting discrimination, Journal of Economic Perspectives, 12:2, 101-116. 
Jian, L., MacKie-Mason, .J., K., and Resnick, P. (2010). I scratched yours: The Prevalence of Reciprocation in Feedback Provision on eBay, The B. E. Journal of Economic Analysis \& Policy, 10:1, 92.

Johansson-Stenman, O., Mahmud, M., and Martinsson, P. (2009). Trust and Religion: Experimental Evidence from Rural Bangladesh, Economica, 76, 462-485.

List, J. (2004). The Nature and Extent of Discrimination in the Marketplace: Evidence from the Field, The Quarterly Journal of Economics, 119:1, 49-89.

Livingstone, J., A. (2005). How valuable is a good reputation? A sample selection model of internet auctions, The Review of Economics and Statistics, 87:3, 453-465.

Livingstone, J., A., List, J. (2010). When the Weak Become Weaker: The Effect of Market Power and Third Degree Price Discrimination, The Selected Works of Jeffrey A

Livingston Available at: http://works.bepress.com/jeffrey_livingston/11.

Lucking-Reiley, D., Bryan, D., Prasad, N., and Reeves, D. (2007). Pennies from eBay: The Determinants of Price in Online Auctions, Journal of Industrial Economics, 55:2, 223-233.

Lynn, M., Sturman, M., Ganley, C., Adams, E., Douglas, M., and McNeil, J. (2008). Consumer Racial Discrimination in Tipping: A Replication and Extension, Journal of Applied Social Psychology, 38:4, 1045-1060.

Nunley, J., M., Owens, M., F., and Howard, S., R. (2011). The effects of information and competition on racial discrimination: Evidence from a field experiment, Journal of Economic Behavior and Organization, 80, 670-679.

Ostrom, E., and Walker, J. (eds.). (2005). Trust and Reciprocity. A Volume in the Russell Sage Foundation Series on Trust. Russell Sage Foundation.

Pager, D., and Shepherd, H. (2008). The Sociology of Discrimination in Employment, Housing, Credit and Consumer Markets, Annual Review of Sociology, 34, 181-209.

Phelps, E., S. (1972). The statistical theory of racism and sexism, American Economic Review, $62: 4,659-61$.

Przepiorka, W. (2012). Ethic Discrimination and Signals of Trustworthiness in an Online Market: Evidence from Two Field Experiments, Nuffield centre for experimental social sciences, Discrussion paper series, 20012:002.

Resnick, P., Zeckhauser, R. (2002). Trust among strangers in internet transactions: Empirical analysis of ebay's reputation system, Advances in Applied Microeconomics, 11, 127-157.

Resnick, P., Zeckhauser, R., Swanson, J., and Lockwood, K. (2006). The value of reputation on eBay: A controlled experiment, Experimental Economics, 9:2, 79-101. 
Riach, P., A., and Rich, J. (2002). Field Experiments of Discrimination in the Market Place, The Economic Journal , 112:483, F480-F518.

Roth, and Ockenfels, A. (2002). Last-Minute Bidding and the Rules for Ending Second-Price Auctions: Evidence from eBay and Amazon Auctions on the Internet, American Economic Review, 92:4, 1093-1103.

Statistics Sweden, Investments, R\&D, IT Unit. (2010) Use of computers and the Internet by private persons in 2009. ISSN 1654-7624.

Shohat, M., and Musch, J. (2003). Online auctions as a research tool: A field experiment on ethnic discrimination, Swiss Journal of Psychology, 62:2, 139-145.

Slonim, R., and Guillen, P. (2010). Gender selection Discrimination: Evidence from a Trust game, Journal of Economic Behavior and Organization, 76, 385-405.

Yinger, J. (1998). Evidence on Discrimination in Consumer Markets, The Journal of Economic Perspectives, 12: 2, 23-40. 


\section{Appendix}

Table. A1: Summary of market in August 2011, August and September 2012

\begin{tabular}{llll}
\hline & August-11 & August-12 & September-12 \\
\hline Average price & 151.27 & 148.52 & 148.58 \\
Buyer negative* & 0.54 & 0.32 & 0.23 \\
New Buyer** & 0.13 & 0.20 & 0.23 \\
Anonymous*** & 0.45 & 0.50 & 0.59 \\
\hline
\end{tabular}

* 1 if buyer has at least 1 pieces of negative feedback at end of auction, 0 otherwise.

$* * 1$ if buyer has 5 or less pieces of feedback at end of auction, 0 otherwise.

$* * * 1$ if username contains is anonymous (does not contain any information of gender and foreignness), 0 otherwise.

Table A2. Full name and username of the sellers.

\begin{tabular}{llll}
\hline Name & Surname & Username & Name category* \\
\hline Daniel & Johansson & daniel012 & MNS, 1 \\
Tomas & Larsson & tomas012 & MNS, 1 \\
Savas & Calsikan & Savasc & MFS, 2 \\
Alireza & Behtuoi & alirezaB & MFS, 2 \\
Pernilla & Andersson & pernilla04 & FNS, 3 \\
Tone & Johansson & tone012 & FNS, 3 \\
Khadra & Seerar & khadra01 & FFS, 4 \\
Afamia & Maraha & Afamia & FFS, 4 \\
Karl-Göran & Karlsson & kgka & MNS, 5 \\
Fredrik & Mattsson & frmat & MNS, 5 \\
Hossein & Ali & hoal01 & MFS, 6 \\
Tiglat & Maraha & tima01 & MFS, 6 \\
Louise & Johanesson & lojo01 & FNS, 7 \\
Eva & Karlsson & evka0 & FNS, 7 \\
Fatima & Nekshbandi & fane01 & FFS, 8 \\
Doaa & Mohamed & domo01 & FFS, 8
\end{tabular}

*Name categories: MNS=Males with non-foreign names, FNS=Females with non-foreign names, MFS=Males with foreign names, FFS=Females with foreign names. MNS=Males with non-foreign names, FNS=Females with nonforeign names, MFS=Males with foreign names, FFS=Females with foreign names. Categories 1-4 reveal their names in the usernames, and name categories 5-8 conceal their names in their usernames. 


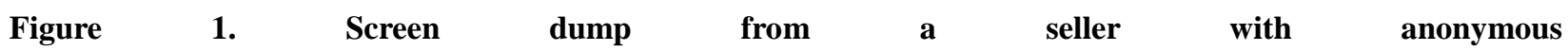
username.

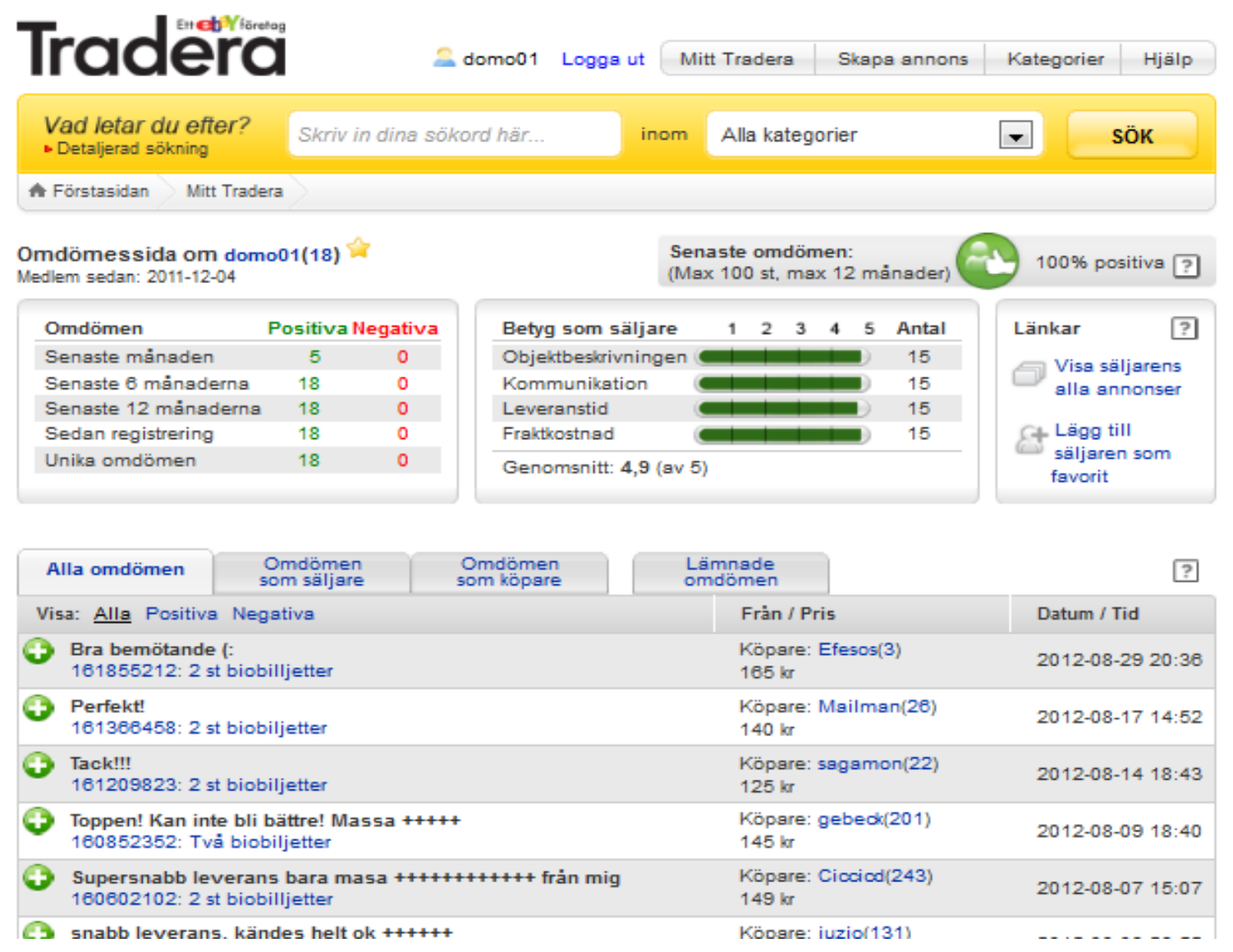

*domo01 had at this point in time 18 unique pieces of feedback from previous auctions.

Table A3. Summary of main variables when being able to select and not.

\begin{tabular}{llllllll}
\hline \multirow{2}{*}{ Variables } & \multicolumn{2}{l}{ Non-anonymous } & \multicolumn{3}{c}{ Anonymous } & \multicolumn{2}{c}{ t-test } \\
& Mean & Sd & N & Mean & Sd & N & p-value \\
\hline Price & 140.00 & 10.99 & 206 & 140.42 & 10.29 & 202 & 0.59 \\
Feedback & 0.70 & 0.46 & 198 & 0.70 & 0.46 & 193 & 0.96 \\
Time to payment* & 2.37 & 2.47 & 198 & 2.31 & 2.77 & 193 & 0.80 \\
Time to feedback** & 7.83 & 8.90 & 137 & 8.90 & 10.71 & 133 & 0.36 \\
\hline
\end{tabular}

*Counted from the day the auction ended.

** Counted from the day the auction ended.

Table. A4. Differences in buyer characteristics for non-anonymous and anonymous usernames

\begin{tabular}{llllll}
\hline & $\begin{array}{l}\text { Non-anonymous } \\
\text { Mean }\end{array}$ & $\mathbf{N}$ & $\begin{array}{l}\text { Anonymous } \\
\text { Mean }\end{array}$ & N & $\begin{array}{l}\text { t-test } \\
\text { p-value }\end{array}$ \\
\hline Female & 0.56 & 217 & 0.44 & 209 & $0.052^{*}$ \\
Foreign name & 0.34 & 217 & 0.36 & 209 & 0.628
\end{tabular}




\begin{tabular}{llllll} 
Large city & 0.49 & 217 & 0.48 & 209 & 0.914 \\
New & 0.27 & 217 & 0.32 & 209 & 0.286 \\
Has negative & 0.34 & 217 & 0.29 & 209 & 0.277 \\
\hline
\end{tabular}

$* * * \mathrm{p}<0.01, * * \mathrm{p}<0.05, * \mathrm{p}<0.1$.

Table A5: Willingness to pay for different groups compared to baseline*

\begin{tabular}{llll}
\hline & Mean for group & Baseline & p-value \\
\hline MNS & 140.64 & 140.38 & 0.874 \\
FNS & 139.81 & 140.38 & 0.703 \\
MFS & 138.63 & 140.38 & 0.225 \\
FFS & 140.80 & 140.38 & 0.784 \\
\hline
\end{tabular}

MNS=Males with non-foreign names, FNS=Females with non-foreign names, MFS=Males with foreign names, FFS=Females with foreign names.

* Baseline is the mean in the group with anonymous usernames

Table A6: Willingness to pay, additional control variables

\begin{tabular}{lll}
\hline VARIABLES & Non-anonymous & p-value \\
\hline New seller & -10.700 & 0.000 \\
Female buyer & -1.681 & 0.259 \\
Non-foreign buyer & 0.666 & 0.708 \\
\# feedbacks buyer & -0.003 & 0.034 \\
Buyer has negative & 1.948 & 0.263 \\
New buyer & 1.567 & 0.358 \\
Big city & 2.240 & 0.151 \\
Day effect & 0.008 & 0.667 \\
\# bids & 0.004 & 0.933
\end{tabular}

Willingness to pay, comparing the other name categories

\begin{tabular}{lll}
\hline MNS vs. FNS & -1.871 & 0.322 \\
MNS vs. FFS & -0.971 & 0.632 \\
FNS vs. FFS & 0.900 & 0.625
\end{tabular}

MNS=Males with non-foreign names, FNS=Females with non-foreign names, FFS=Females with foreign names.

Table A7a: Share of feedback, additional control variables

\begin{tabular}{lllll}
\hline VARIABLES & Non-anonymous & p-value & Anonymous & p-value \\
\hline Feedback first & & & & \\
New seller & 0.679 & 0.000 & 0.652 & 0.000 \\
Female buyer & -0.042 & 0.453 & 0.008 & 0.895 \\
Non-foreign buyer & -0.142 & 0.001 & -0.005 & 0.921 \\
\# feedbacks buyer & -0.074 & 0.142 & 0.048 & 0.407 \\
Buyer has negative & 0.000 & 0.021 & 0.000 & 0.399 \\
New buyer & -0.082 & 0.119 & 0.014 & 0.822 \\
Big city & -0.138 & 0.003 & -0.059 & 0.344 \\
Day effect & -0.051 & 0.250 & -0.093 & 0.055 \\
\# bids & 0.000 & 0.595 & -0.000 & 0.715 \\
Price & 0.002 & 0.257 & -0.002 & 0.087 \\
& 0.002 & 0.384 & -0.005 & 0.064 \\
Share of feedback, comparing the other name categories & & \\
\hline MNS vs. FNS & 0.104 & 0.064 & 0.007 & 0.910 \\
MNS vs. FFS & 0.083 & 0.100 & -0.090 & 0.166
\end{tabular}


MNS=Males with non-foreign names, FNS=Females with non-foreign names, FFS=Females with foreign names.

Table A7b: Share of feedback, buyers that provided feedback before sellers provided feedback

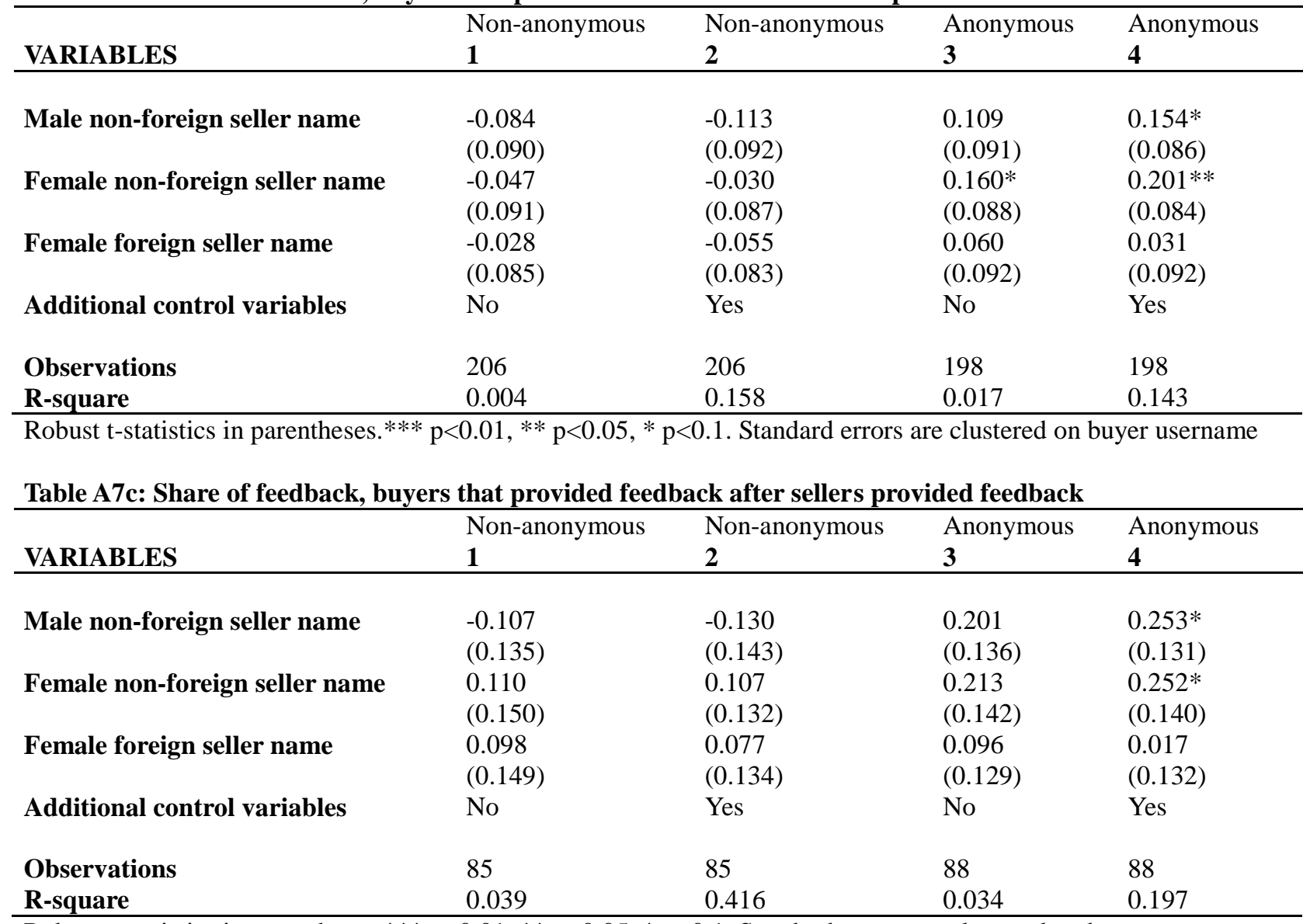

Robust t-statistics in parentheses. $* * * \mathrm{p}<0.01, * * \mathrm{p}<0.05, * \mathrm{p}<0.1$. Standard errors are clustered on buyer username

Table A7d: Share of feedback, separately by female and male buyers. Non-anonymous seller groups.

\begin{tabular}{|c|c|c|c|c|}
\hline VARIABLES & Women & Women & Men & Men \\
\hline Male non-foreign seller name & $\begin{array}{c}0.312 * * \\
(0.140)\end{array}$ & $\begin{array}{c}0.249 * * \\
(0.105)\end{array}$ & $\begin{array}{l}-0.037 \\
(0.117)\end{array}$ & $\begin{array}{c}0.073 \\
(0.082)\end{array}$ \\
\hline Female non-foreign seller name & $\begin{array}{l}0.256 * \\
(0.137)\end{array}$ & $\begin{array}{l}0.194 * \\
(0.101)\end{array}$ & $\begin{array}{c}0.078 \\
(0.116)\end{array}$ & $\begin{array}{c}0.104 \\
(0.071)\end{array}$ \\
\hline Female foreign seller name & $\begin{array}{c}0.212 \\
(0.132)\end{array}$ & $\begin{array}{l}0.176 * \\
(0.099)\end{array}$ & $\begin{array}{l}-0.104 \\
(0.137)\end{array}$ & $\begin{array}{l}-0.060 \\
(0.074)\end{array}$ \\
\hline Additional control variables & No & Yes & No & Yes \\
\hline $\begin{array}{l}\text { Observations } \\
\text { R-square }\end{array}$ & $\begin{array}{c}89 \\
0.065\end{array}$ & $\begin{array}{c}89 \\
0.629\end{array}$ & $\begin{array}{c}109 \\
0.019\end{array}$ & $\begin{array}{c}109 \\
0.596\end{array}$ \\
\hline
\end{tabular}

Robust t-statistics in parentheses. $* * * \mathrm{p}<0.01, * * \mathrm{p}<0.05, * \mathrm{p}<0.1$. Standard errors are clustered on buyer username 
Table 8a. Number of days to payment.

\begin{tabular}{lllll}
\hline VARIABLES & Non-anonymous & Non-anonymous & Anonymous & Anonymous \\
$\mathbf{2}$ & $\mathbf{1}$ & $\mathbf{2}$ & $\mathbf{3}$ & $\mathbf{4}$ \\
\hline Male non-foreign seller name & & & & 0.637 \\
& -0.672 & -0.542 & 0.714 & $(0.435)$ \\
Female non-foreign seller name & $(0.467)$ & $(0.477)$ & $(0.487)$ & 0.422 \\
& -0.615 & -0.560 & $0.580^{*}$ & $(0.363)$ \\
Female foreign seller name & $(0.549)$ & $(0.566)$ & $(0.340)$ & $1.382^{* *}$ \\
& -0.351 & -0.281 & $1.280^{* *}$ & $(0.609)$ \\
Additional control variables & $(0.534)$ & $(0.521)$ & $(0.567)$ & Yes \\
& & & No & \\
Observations & No & Yes & & 198 \\
R-squared & & & 0.028 \\
\hline Robust t-statistics in parentheses. ${ }^{* * *} \mathrm{p}<0.01, * * \mathrm{p}<0.05, * \mathrm{p}<0.1$. Standard errors are clustered on buyer username
\end{tabular}

Table A8b: Time to payment, additional control variables

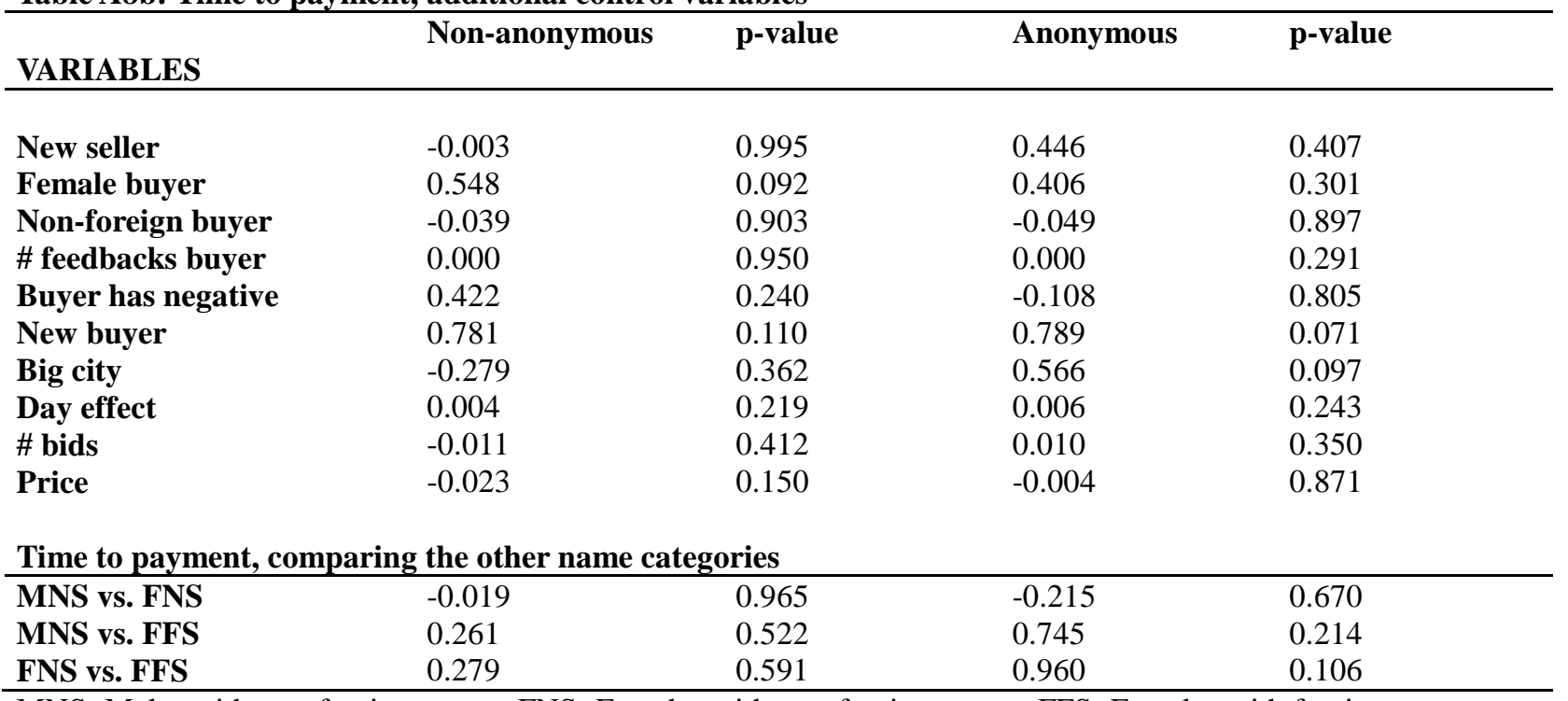

MNS=Males with non-foreign names, FNS=Females with non-foreign names, FFS=Females with foreign names.

Table A8c: Time to payment, buyers that provided feedback vs. buyers that did not provide feedback

\begin{tabular}{lllll}
\hline VARIABLES & No feedback & & \multicolumn{2}{l}{ Feedback } \\
\hline Male non-foreign seller name & & & & \\
& & & & 0.103 \\
& 2.211 & $(1.617)$ & $(0.321)$ & $(0.348)$ \\
Female non-foreign seller name & $(1.524)$ & 1.182 & 0.452 & 0.295 \\
& 1.211 & $(1.086)$ & $(0.382)$ & $(0.417)$ \\
Female foreign seller name & $(0.744)$ & $3.573 * *$ & 0.510 & 0.430 \\
Additional control variables & $2.961 *$ & $(1.750)$ & $(0.340)$ & $(0.365)$ \\
Observations & $(1.553)$ & Yes & No & Yes \\
R-square & No & & & 139 \\
\hline
\end{tabular}


Robust t-statistics in parentheses. $* * * \mathrm{p}<0.01, * * \mathrm{p}<0.05, * \mathrm{p}<0.1$. Standard errors are clustered on buyer username

Table A9a. Number of days to feedback.

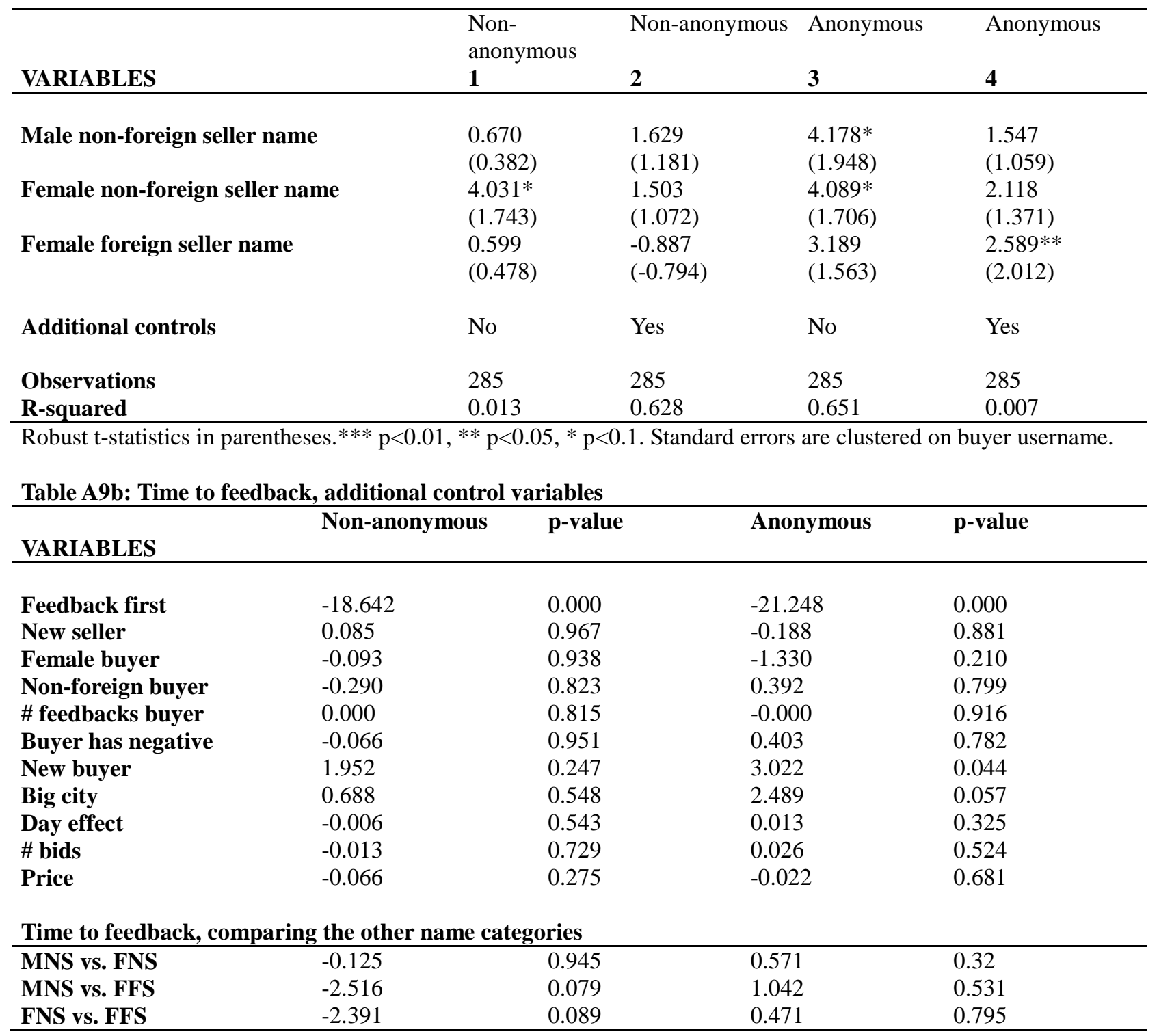

MNS=Males with non-foreign names, FNS=Females with non-foreign names, FFS=Females with foreign names. 